\title{
Study of cluster headache: A hospital-based study
}

\author{
Amita Bhargava, Guruprasad S. Pujar, Basavaraj F. Banakar, Shubhakaran K, Gaurav Kasundra, Bharat Bhushan \\ Department of Neurology, Dr. S. N Medical College Jodhpur, Rajasthan, India
}

\begin{abstract}
Introduction: Cluster headache $(\mathrm{CH})$ is uncommon and most painful of all primary headaches, and continues to be managed suboptimally because of wrong diagnosis. It needs to be diagnosed correctly and specifically treated. There are few studies and none from this region on $\mathrm{CH}$. Materials and Methods: To study the detailed clinical profile of $\mathrm{CH}$ patients and to compare them among both the genders. Study was conducted at Mahatma Gandhi hospital, Jodhpur (from January 2011to December 2013). Study comprises $30 \mathrm{CH}$ patients diagnosed according to International Headache Society guidelines (ICHD-II). Routine investigations and MRI brain was done in all patients. All measurements were reported as mean \pm SD. Categorical variables were compared using the Chi-square test, and continuous variables were compared using Student's $t$-test. SPSS for Windows, Version 16.o, was used for statistical analyses with the significance level set at $P=0.05$. Results: M: F ratio was 9:1. Age at presentation was from 22-6o years (mean - 38 years). Latency before diagnosis was 3 months-12 years (mean - 3.5 years). All suffered from episodic $\mathrm{CH}$ and aura was found in none. Pain was strictly unilateral (right-19, left-11), predominantly over temporal region-18 (60\%). Pain intensity was severe in 27 (90\%) and moderate in $3(10 \%)$. Pain quality was throbbing in $12(40 \%)$. Peak intensity was reached in 5 minutes-30 minutes and attack duration varied from 30 minutes to 3 hours (mean - 2.45 hours). Among autonomic features, conjunctival injection-23 (76.6\%) and lacrimation-25 (83.3\%) were most common. Restlessness during episode was found in $80 \%$. CH duration varied from 10 days to 12 weeks. Circadian periodicity for attacks was noted in $24(80 \%)$. Conclusion: Results are consistent with other studies on many accounts, but is different from Western studies with respect to low frequency of family history, chronic $\mathrm{CH}$, restlessness and aura preceeding the attack. Detailed elicitation of history is paramount as misdiagnosis is common.
\end{abstract}

Key words: Autonomic, cluster headache, trigeminal

\section{Introduction}

Cluster headache $(\mathrm{CH})$ is an excruciating primary headache syndrome, which is strictly unilateral pain usually involving the orbital or periorbital region innervated by the first (ophthalmic) division of the trigeminal nerve and is accompanied by ipsilateral autonomic features, including lacrimation, conjunctival injection, nasal congestion and/or rhinorrhea, ptosis and/or miosis, and periorbital edema. $\mathrm{CH}$ show male predominance, and striking circannual and circadian periodicity. ${ }^{[1,2]}$ The prevalence of $\mathrm{CH}$ is estimated to be $0.1-0.4 \%$. Most of the literature about $\mathrm{CH}$ is derived from Western studies. ${ }^{[3,4]}$ This study is done to know the

\begin{tabular}{|c|l|}
\hline \multicolumn{2}{|c|}{ Access this article online } \\
\hline Quick Response Code: & Website: \\
\hline & www.ruralneuropractice.com \\
\cline { 2 - 2 } & \\
\hline & \\
\hline
\end{tabular}

detailed clinical characteristics of $\mathrm{CH}$ patients in this part of the India.

\section{Materials and Methods}

It is a hospital-based prospective study conducted at department of Neurology, M G hospital, Dr S N Medical college, Jodhpur, Rajasthan, between January 2011 and December 2013. The study population consisted of Patients diagnosed with $\mathrm{CH}$, as defined by the second edition of the International Classification of Headache Disorders (ICHD-II), ${ }^{[5]}$ attending neurology unit.

All patients underwent detailed clinical evaluation by two consultants. Data was recorded with respect to disease course, location, laterality, quality, intensity and radiation of pain, frequency, duration, periodicity of attacks, duration of clusters. Possible trigger factors, autonomic features, additional features (e.g. nausea, vomiting, photophobia, phonophobia, behaviors during attacks), family history of headache, history of smoking and drinking were all noted. Patients were classified as

Address for correspondence:

Dr. Guruprasad S. Pujar, Department of Neurology, M. G. Hospital, Jodhpur, Rajasthan, India. E-mail: drgurupujar@gmail.com 
episodic or chronic $\mathrm{CH}$ types. Brain imaging (MRI), with routine hematological and biochemical investigations were done in all patients. MRI brain was done to rule out underlying intracranial or neck structural lesions such as neoplasms, vascular malformations, and cervicocephalic arterial aneurysms/dissections which can present as cluster-like headaches.

Treatment was individualized. Subcutaneous and intranasal sumatriptan was not routinely prescribed in view of its cost, except for few urban literate patients. Corticosteroids and ergotamine were used as emergency measures. For those with longer bouts, verapamil was given for appropriate period of time.

\section{Results}

\section{Study population}

A total of 33 consecutive $\mathrm{CH}$ patients were evaluated during the study period. Three patients were excluded as one of the patients also had the features of trigeminal neuralgia, other had features of paroxysmal hemicrania, and in third case it was his first presentation which didn't fulfill the criteria of ICHD-II. Out of remaining 30 patients, $27(90 \%)$ were males and $3(10 \%)$ were females, giving a male-to-female (M: F) ratio of 9:1. All our patients had episodic $\mathrm{CH}(100 \%)$. Mean age at presentation was $38.8 \pm 13.5$ years (range 22-68 years) (males, $39.5 \pm 13.93$ years vs. females, $32.3 \pm 8.02$ years). The mean age at onset was $35.14 \pm 14$ years (range 20-67 years) (males $35.8 \pm 14.6$ years vs. females $31.3 \pm 8.08$ years, $P=0.607)$ [Table 1]. Two patients $(6.6 \%, 2 \mathrm{M})$ also had tension-type headache and one had migraine headache $(1 \mathrm{~F})$. Time lag before diagnosis was 3 months to 12 years (3.5 years) [Table 2]. All our patients had consulted other medical clinics and had been referred from other doctors, and none of them had previously been diagnosed with $\mathrm{CH}$.

\section{Sites and laterality of headache}

Pain was strictly unilateral right-19 (63.3\%), left-11 $(36.6 \%)$ and was predominantly over temporal region-18 (60\%) followed by orbital-16 (53.3\%), forehead-2 (6.6\%), and parietal-2 (6.6\%). Pain intensity was severe in $27(90 \%)$ and moderate in $3(10 \%)$. Pain quality was throbbing in $12(40 \%)$, followed by stabbing-10 (33.3\%), burning-6 (20\%), and boring in $2(6.6 \%)$. Peak intensity of pain was reached within 5 to 30 minutes (mean $=18.8$ minutes) [Table 3].

Cranial autonomic and additional features in patients with $\mathbf{C H}$

None of our patients experienced any kind of aura prior to attacks. Among autonomic features, lacrimation-25 (83.3\%) was most common followed by conjunctival injection-23 (76.6\%), rhinorrhea-11 (36.6\%), nasal congestion-7 (23.3\%), and less commonly, facial sweating-2 (6.6\%), Ptosis-5 (16.7\%). Other associated features during the attacks were nausea/vomiting-9 $(30 \%)$, photophobia-10 (33.3\%), phonophobia-12 (40\%) and restlessness $(80 \%)$. There was no statistically significant difference in any of the clinical characteristics between male and female patients [Table 4].

\section{Periodicity of Cluster headache}

Regarding frequency of cluster periods we observed that majority had $<1$ cluster period/year-20 (66.6\%), followed

Table 1: Demographic profile

\begin{tabular}{lcccc}
\hline $\begin{array}{l}\text { Patient } \\
\text { characteristics }\end{array}$ & $\begin{array}{c}\text { Total } \\
(\boldsymbol{n}=\mathbf{3 0})\end{array}$ & $\begin{array}{c}\text { Males } \\
(\boldsymbol{n}=\mathbf{2 7})\end{array}$ & $\begin{array}{c}\text { Females } \\
(\boldsymbol{n}=\mathbf{0 3})\end{array}$ & $\boldsymbol{P}$ value \\
\hline $\begin{array}{l}\text { Type of cluster } \\
\text { headache }\end{array}$ & & & & \\
$\begin{array}{l}\text { Episodic } \\
\text { Chronic }\end{array}$ & 30 & 27 & 03 & 1.00 \\
$\begin{array}{l}\text { Age at presentation } \\
\text { in years (mean } \pm S D)\end{array}$ & $38.8 \pm 13.5$ & $39.5 \pm 13.93$ & $32.3 \pm 8.02$ & 0.393 \\
$\begin{array}{l}\text { Age at onset in } \\
\text { years (mean } \pm S D)\end{array}$ & $35.4 \pm 14.0$ & $35.8 \pm 14.6$ & $31.3 \pm 8.08$ & 0.607 \\
$\begin{array}{l}\text { Family history } \\
\text { SD - Standard deviation }\end{array}$ & 0 & 0 & 0 & 0 \\
\hline
\end{tabular}

Table 2: Latency before diagnosis

\begin{tabular}{lccc}
\hline & Total $(\boldsymbol{N = 3 0 )}$ & Male $(\mathbf{N = 2 7 )}$ & Female $(\mathbf{N = 0 3 )}$ \\
\hline Time before diagnosis & & & \\
Less than 1 year & $6(20)$ & $4(14.8)$ & $2(66.6)$ \\
From 1 to 5 years & $17(56.6)$ & $16(59.2)$ & $1(33.3)$ \\
From 6 to 10 years & $5(16.6)$ & $4(14.8)$ & 0 \\
More than 10 years & $2(6.6)$ & $2(7.4)$ & 0 \\
\hline
\end{tabular}

Results are reported as number of patients (percent)

Table 3: Characteristics of pain

\begin{tabular}{|c|c|c|c|c|}
\hline & $\begin{array}{c}\text { Total } \\
(n=30)\end{array}$ & $\begin{array}{l}\text { Males } \\
(n=27)\end{array}$ & $\begin{array}{c}\text { Females } \\
(n=03)\end{array}$ & $P$ value \\
\hline \multicolumn{5}{|l|}{ Sites of pain } \\
\hline Temporal & $18(60)$ & $15(55.5)$ & $3(100)$ & 0.497 \\
\hline Orbital & $16(53.3)$ & $14(51.8)$ & 2 (66.6) & 1 \\
\hline Parietal & $2(6.6)$ & $2(7.4)$ & 0 & 1 \\
\hline forehead & $2(6.6)$ & $2(7.4)$ & 0 & 1 \\
\hline \multicolumn{5}{|c|}{ Laterality of pain } \\
\hline Right side & 19 (63.3) & $17(62.96)$ & $2(66.6)$ & 1 \\
\hline Left side & $11(36.6)$ & $10(37.03)$ & $1(33.3)$ & \\
\hline \multicolumn{5}{|c|}{ Quality of pain } \\
\hline Stabbing & 10 (33.3) & 9 (33.3) & $1(33.3)$ & 1 \\
\hline Throbbing & $12(40)$ & $11(40.7)$ & $1(33.3)$ & 1 \\
\hline Burning & $6(20)$ & $6(22.2)$ & 0 & 1 \\
\hline Boring & $2(6.6)$ & $1(3.7)$ & $1(33.3)$ & 0.1871 \\
\hline \multicolumn{5}{|c|}{ Pain intensity } \\
\hline Mild & 0 & 0 & 0 & \\
\hline Moderate & $3(10)$ & $3(11.1)$ & 0 & 1 \\
\hline Severe & $27(90)$ & $24(88.8)$ & $3(100)$ & 1 \\
\hline
\end{tabular}


by irregular clusters-7 (23.3\%), 1-2 cluster periods/ year-2 $(6.6 \%)$ and $3.3 \%$ had $>2$ cluster periods per year. The duration of cluster periods were 2 weeks to less than 1 month in 12 (40\%), 1-2 months in 11 (36.6\%) of patients, less than 2 weeks in 4 (13.3\%) and more than 2 months in $10 \%$. Attacks occurred 1-2 times per day in 19 (63.3\%) of patients, $>2$ times/day in $10(33.3 \%)$ and $<1$ time per day in $3.3 \%$. We observed that each attack ranged in duration from $1 \mathrm{~h}$ to less than $2 \mathrm{~h}$ in $12(40 \%)$ and from 2 to $3 \mathrm{~h}$ in 16 (53.2\%) of patients. Other $6.6 \%$ patients comment on the attack duration as less than $1 \mathrm{~h}$ [Table 4]. Circadian periodicity for attacks was noted in 25 (83.3\%) with (2 PM-5 PM, 12 AM-4 AM) as most common.

\section{Table 4: Associated autonomic features}

\begin{tabular}{lcccc}
\hline & $\begin{array}{c}\text { Total } \\
(\boldsymbol{n}=\mathbf{3 0})\end{array}$ & $\begin{array}{c}\text { Males } \\
(\boldsymbol{n}=\mathbf{2 7})\end{array}$ & $\begin{array}{c}\text { Females } \\
(\boldsymbol{n}=\mathbf{0 3})\end{array}$ & $\boldsymbol{P}$ value \\
\hline Autonomic features & & & & \\
$\quad$ Lacrimation & $25(83.3)$ & $22(81.4)$ & $3(100)$ & 1 \\
Conjunctival injection & $23(76.6)$ & $20(74.07)$ & $3(100)$ & 1 \\
Rhinorrhea & $11(36.6)$ & $10(37.03)$ & $1(33.3)$ & 1 \\
Nasal congestion & $7(23.3)$ & $6(22.2)$ & $1(33.3)$ & 1 \\
Ptosis/miosis & $5(16.6)$ & $5(18.51)$ & 0 & 1 \\
Facial sweating & $2(6.6)$ & $2(7.40)$ & 0 & 1 \\
Blepharedema & 0 & 0 & 0 & \\
Additional features & \multicolumn{5}{c}{0} & \\
$\quad$ Nausea & $9(30)$ & $9(33.3)$ & 0 & 1 \\
Vomiting & $9(30)$ & $9(33.3)$ & 0 & 1 \\
Photophobia & $10(33.3)$ & $9(33.3)$ & $1(33.3)$ & 0.49 \\
Phonophobia & $12(40)$ & $10(37.03)$ & $2(66.6)$ & 0.13 \\
Restlessness & $24(80)$ & $22(81.4)$ & $2(66.6)$ & \\
Aura & 0 & & & \\
\hline Results are reported as number of patients (percent) &
\end{tabular}

Table 5: Characteristics of cluster episodes

\begin{tabular}{lccc}
\hline & $\begin{array}{c}\text { Total } \\
(\boldsymbol{n}=\mathbf{3 0})\end{array}$ & $\begin{array}{c}\text { Males } \\
(\boldsymbol{n}=\mathbf{2 7})\end{array}$ & $\begin{array}{c}\text { Females } \\
(\boldsymbol{n}=\mathbf{0 3})\end{array}$ \\
\hline Frequency of clusters & & & \\
$\quad$ More than 2 times/year & $1(3.3)$ & $1(3.7)$ & 0 \\
1-2 times/year & $2(6.6)$ & $2(7.4)$ & 0 \\
Less than 1 time/year & $20(66.6)$ & $17(62.9)$ & $3(100)$ \\
Irregular & $7(23.3)$ & $7(25.9)$ & \\
Duration of clusters & & & \\
Less than 2 weaks & $4(13.3)$ & $3(11.1)$ & $1(33.3)$ \\
2 weaks-1 month & $12(40)$ & $10(37.03)$ & $2(66.6)$ \\
From 1 to 2 months & $11(36.6)$ & $11(40.74)$ & 0 \\
$\quad$ More than 2 months & $3(10)$ & $3(11.1)$ & 0 \\
Frequency of attacks & & & \\
More than 2 times/day & $10(33.3)$ & $8(29.6)$ & $2(66.6)$ \\
1-2 times/day & $19(63.3)$ & $18(66.6)$ & $1(33.3)$ \\
Less than 1/day & $1(3.3)$ & $1(3.7)$ & 0 \\
Duration of attacks & & & \\
Less than 1 hour & $2(6.6)$ & $2(7.4)$ & 0 \\
From 1-2 hour & $12(40)$ & $11(40.74)$ & $1(33.3)$ \\
From 2-3 hour & $16(53.3)$ & $14(51.8)$ & $2(66.6)$ \\
More than 3 hour & 0 & & \\
\hline Results are reported as number of patients (percent) &
\end{tabular}

In $19(63.3 \%)$ patients attacks were seen both during nocturnal and day time, only during day in $9(30 \%)$ and only nocturnal in $2(6.6 \%)$ [Table 5].

\section{Other features}

Seasonal predilection was seen in $46 \%$ of patients, summer $(30 \%)$, winter $(16 \%)$. Sixteen $(53.4 \%)$ patients were smokers, $8(27 \%)$ were tobacco chewers and $3(10 \%)$ were alcoholics [Table 6].

\section{Discussion}

Though patients of headache form the main bulk of outpatient clinics in hospitals, the time it receives by the clinicians is often less leading to misdiagnosis and prolonged suffering to the patient. Keen observation and extra dedication may prevent trigeminal autonomic cephalalgias being dismissed as tension type or migrainous headache. There are very few studies on $\mathrm{CH}$ in India. Over a period of 3 years we came across 30 patients of $\mathrm{CH}$ in a busy outpatient clinic of a medical college hospital. There are many similarities and few dissimilarities in clinical characteristics of our patients with that of other Asian and western studies.

In our study $\mathrm{CH}$ was mainly seen in males than in females with a ratio of 9:1. This was almost similar to that seen from other Asian studies (Dong Z et al., ${ }^{[6]} 7: 1$, Lin $\mathrm{KH}$ et al., ${ }^{[7]}$ 6.4:1) and much higher than western studies. ${ }^{[8]}$ Decreasing trend for M/F ratio is observed in western studies possibly because of life style changes adopted by females. Majority (46.6\%) of our patients had their onset of $\mathrm{CH}$ in the third decade of life, which was also found in other studies. ${ }^{[6-8]}$ Although positive family history has been reported in $1.9 \%$ to $6.7 \%$ of patients with $\mathrm{CH}$ by Bharar et al., ${ }^{[8]}$ we didn't find that in any of our patients. But the time lag prior to correct diagnosis was between 3 months and 12 years (mean $=3.5$ years), which highlights the fact about the lack of awareness of this condition and the need to educate clinicians to prevent the suffering of the patients.

Though aura preceding the $\mathrm{CH}$ had been described in western studies, ${ }^{[8-10]}$ none of our patients experienced this phenomenon which was similar to Chinese study. ${ }^{[6]}$ This difference may be due to genetic and racial factors.

Most of the literature on $\mathrm{CH}$ mentions orbital/retroorbital region as the predominant site of pain which was found only in $53.3 \%$ of our patients. In our study temporal region $(60 \%)$ was the predominant site of pain which was also found in Japanese ${ }^{[11]}$ and Chinese ${ }^{[6]}$ patients. Western studies ${ }^{[8,9,12]}$ also describe jaw, teeth and maxilla as other sites of pain which was seldom seen in our patients. 
Table 6: Other associated features

\begin{tabular}{lccc}
\hline & $\begin{array}{c}\text { Total } \\
(\boldsymbol{n}=\mathbf{3 0})\end{array}$ & $\begin{array}{c}\text { Males } \\
(\boldsymbol{n}=\mathbf{2 7})\end{array}$ & $\begin{array}{c}\text { Females } \\
(\boldsymbol{n}=\mathbf{0 3})\end{array}$ \\
\hline Periodicity of CH & $19(63.3)$ & $16(59.25)$ & $3(100)$ \\
$\quad$ Nocturnal and day & $9(30)$ & $9(33.3)$ & 0 \\
Day only & $2(6.6)$ & $2(7.4)$ & 0 \\
$\quad$ Nocturnal only & & & \\
Seasonal specificity & $9(30)$ & $9(33.3)$ & 0 \\
$\quad$ Only summer & $5(16.6)$ & $5(18.5)$ & 0 \\
Only winter & $16(53.3)$ & $13(48)$ & $3(100)$ \\
Irregular & & & \\
Association with habits & $16(53.3)$ & $16(59.2 \%)$ & 0 \\
$\quad$ With smoking & $8(27 \%)$ & $8(26 \%)$ & 0 \\
$\quad$ With tobacco & $3(10 \%)$ & $3(11 \%)$ & 0 \\
With alcohol & $6(33.3)$ & $3(11 \%)$ & $3(100)$ \\
$\quad$ No habits & Results are reported as number of patients (percent) &
\end{tabular}

It's a well-known fact that $\mathrm{CH}$ is one of the worst forms of headache, and was agreed upon by $90 \%$ of our patients. As majority of patients were rural folks we found it difficult to use VAS (visual analog scale) for defining pain. But quality of pain was described as throbbing $(40 \%)$ and stabbing $(33.3 \%)$ in our patients in contrast to earlier Indian studies by Chakravarty ${ }^{[13]}$ and Ravishankar, ${ }^{[14]}$ where burning and boring quality was predominant. As intensity and quality of pain is a subjective phenomenon, these differences could be due to the cultural and educational background of the patients. The associated autonomic symptoms which is the defining feature of these headaches was found in our patients as similar to that of other Indian ${ }^{[13]}$ and Asian studies. ${ }^{[6,7]}$

Feeling of restlessness and manifesting as restless behavior, as two separate entities was described by Imai et al. ${ }^{[11]}$ in their Japanese patients. True to his description we found that though $80 \%$ patients had feeling of restlessness, felt as sense of agitation and anxiety, only $46 \%$ showed restless behavior in the form of pacing around. Cultural differences, where in patience is emphasized by eastern culture was explained as one of the reasons for patients remaining still despite feelings of restlessness.

The clock-like rhythmicity and periodicity which is the characteristic feature of $\mathrm{CH}$ had been attributed to biological clock in suprachiasmatic nucleus of hypothalamus, the evidence for which comes from functional and morphometric imaging using PET scans by may et al. ${ }^{[15]}$ Though many studies describe attacks to be common during nocturnal hours, we found that $63.5 \%$ of our patients had attacks both during day and nocturnal hours which is similar to other Indian ${ }^{[13]}$ and
Chinese study ${ }^{[6]}$ In $80 \%$ of patients attacks commonly occurred from $2 \mathrm{PM}$ to $5 \mathrm{PM}$ and from $12 \mathrm{AM}$ to 4 AM.

Seasonal Predilection- $\mathrm{CH}$ is considered a circadian-based syndrome, and its seasonal occurrence was first noted by Ekbom ${ }^{[16]}$ and Kudrow. ${ }^{[17]}$ This pattern was seen in around $46 \%$ of our patients, where recurrence was only in summers in $30 \%$, and only during winters in the remaining.

Lifestyle factors and Cluster Headache- It has received much attention from western studies (Rozen, ${ }^{[9]}$ Manzoni ${ }^{[18]}$ ) who have observed association of $\mathrm{CH}$ and smoking in around $70 \%$ of their patients, alcohol and coffee abuse in lesser number of patients. Smoking was seen in $53.3 \%$ of our patients, smoking and tobacco combined was observed in $10 \%$. Majority of our patients continued to smoke and consume alcohol even during clusters.

Limitations of our study are the small sample size and the data of which cannot be extrapolated to general population. Recall bias while recording history of previous episodes of clusters. We didn't study the impact of $\mathrm{CH}$ on patient's occupation and quality of life. Further studies with large number of patients, ideally from headache clinics could give better insight about this disease.

Our study is an attempt to describe detailed clinical characteristics of $\mathrm{CH}$ in Indian patients. Results of our study are consistent with those of other Western and Asian studies regarding various demographic and clinical profile, but is different from Western studies with respect to low frequency of family history, chronic $\mathrm{CH}$, restless behavior and aura preceding the attack. These differences could be explained by different genetic, racial, cultural and lifestyle factors between Indian and Western patients. $\mathrm{CH}$ still remains misdiagnosed for years. Increasing the knowledge of $\mathrm{CH}$ among referring clinicians could improve the recognition and treatment of cluster headache.

\section{Acknowledgement}

Dr. Manish Mittal, Dr. Janardhan Sharma, Dr. Yasin.

\section{References}

1. Nesbitt AD, Goadsby PJ Cluster headache. BMJ 2012;344:e2407

2. May A. Cluster headache: Pathogenesis, diagnosis, and management. Lancet 2005;366:843-55.

3. Schurks M, Kurth T, de Jesus J, Jonjic M, Rosskopf D, Diener HC. Cluster headache: Clinical presentation, lifestyle features, and medical treatment. Headache 2006;46:1246-54. 
4. Gaul C, Christmann N, Schröder D, Weber R, Shanib H, Diener HC, et al. Differences in clinical characteristics and frequency of accompanying migraine features in episodic and chronic cluster headache. Cephalalgia 2012;32:571-7.

5. Headache Classification Subcommittee of the International Headache Society. The International Classification of Headache Disorders. $2^{\text {nd }} \mathrm{ed}$. Cephalalgia 2004;24(Suppl 1):60-3.

6. Dong Z, Di H, Dai W, Pan M, Li Z, Liang J, et al. Clinical profile of cluster headaches in China - a clinic-based study. J Headache Pain 2013;14:27.

7. Lin KH, Wang PJ, Fuh JL, Lu SR, Chung CT, Tsou HK, et al. Cluster headache in the Taiwanese - A clinic-based study. Cephalalgia 2004;24:631-8

8. Bahra A, May A, Goadsby PJ. Cluster headache: A prospective clinical study with diagnostic implications. Neurology 2002;58:354-61.

9. Rozen TD, Fishman RS. Cluster headache in the United States of America: Demographics, clinical characteristics, triggers, suicidality, and personal burden. Headache 2012;52:99-113.

10. Rozen TD. Cluster headache with aura. Curr Pain Headache Rep 2011;15:98-100

11. Imai N, Yagi N, Kuroda R, Konishi T, Serizawa M, Kobari M. Clinical profile of cluster headaches in Japan: Low prevalence of chronic cluster headache, and uncoupling of sense and behaviour of restlessness. Cephalalgia 2011;31:628-33.

12. Donnet A, Lanteri-Minet M, Guegan-Massardier E, Mick G, Fabre N, Géraud G, et al. Chronic cluster headache: A French clinical descriptive study. J Neurol Neurosurg Psychiatry 2007;78:1354-8.

13. Chakravarty A. Cluster headache: Clinical profile in Indian patients. Ann Indian Acad Neurol 2001;4:207-9.

14. Ravishankar K. Cluster headache and other short-lasting headaches. Ann Indian Acad Neurol 2002;5:53-8.

15. May A, Bahra A, Buchel C, Frackowiak RS, Goadsby PJ. Hypothalamic activation in cluster headache attacks. Lancet 1998;352:275-8.

16. Ekbom K. A clinical comparison of cluster headache and migraine. Acta Neurol Scand 1970;46:1-48.

17. Kudrow L. Cluster Headache: Mechanisms and Management. New York: Oxford University Press; 1980.

18. Manzoni GC. Cluster headache and lifestyle: Remarks on a population of 374 male patients. Cephalalgia 1999;19:88-94.

How to cite this article: Bhargava A, Pujar GS, Banakar BF, K S, Kasundra G, Bhushan B. Study of cluster headache: A hospital-based study. J Neurosci Rural Pract 2014;5:369-73.

Source of Support: Nil. Conflict of Interest: None declared. 